\title{
The Relationship between Multiple Health Behaviours and Brachial Artery Reactivity
}

\author{
Jennifer L. Gordon, ${ }^{1,2,3}$ Kim L. Lavoie, ${ }^{1,2,4,5}$ André Arsenault, ${ }^{1,2}$ Bernard Meloche, ${ }^{1,2}$ \\ Blaine Ditto, ${ }^{3}$ Tavis S. Campbell, ${ }^{6}$ and Simon L. Bacon ${ }^{1,2,4,7}$ \\ ${ }^{1}$ Montreal Behavioural Medicine Centre, Montréal, Québec, Canada \\ ${ }^{2}$ Research Centre, Montreal Heart Institute, A University of Montreal Teaching Hospital, Montréal, Québec, Canada H1T 1 C8 \\ ${ }^{3}$ Department of Psychology, McGill University, Montréal, Québec, Canada H3B 1B1 \\ ${ }^{4}$ Research Centre, Sacré-Cour Hospital of Montreal, A University of Montreal Teaching Hospital, Montréal, Québec, Canada H4J 1 C5 \\ ${ }^{5}$ Department of Psychology, University of Québec at Montréal (UQAM), Montréal, Québec, Canada H3C 3P8 \\ ${ }^{6}$ Department of Psychology, University of Calgary, Calgary, Alberta, Canada T2N 1N4 \\ ${ }^{7}$ Department of Exercise Science, Concordia University, 7141 Sherbrooke Street West, SP165.35, Montréal, Québec, Canada H4B 1R6
}

Correspondence should be addressed to Simon L. Bacon, simon.bacon@concordia.ca

Received 20 March 2011; Accepted 29 November 2011

Academic Editor: Douglas Carroll

Copyright (C 2012 Jennifer L. Gordon et al. This is an open access article distributed under the Creative Commons Attribution License, which permits unrestricted use, distribution, and reproduction in any medium, provided the original work is properly cited.

\begin{abstract}
Background. The effects of smoking, alcohol consumption, obesity, and a sedentary lifestyle on endothelial function (EF) have only been examined separately. The relative contributions of these behaviours on EF have therefore not been compared. Purpose. To compare the relative associations between these four risk factors and brachial artery reactivity in the same sample. Methods. 328 patients referred for single-photon emission computed tomography (SPECT) exercise stress tests completed a nuclear-medicinebased forearm hyperaemic reactivity test. Self-reported exercise behaviour, smoking habits, and alcohol consumption were collected and waist circumference was measured. Results. Adjusting for relevant covariates, logistic regression analyses revealed that waist circumference, abstinence from alcohol, and past smoking significantly predicted poor brachial artery reactivity while physical activity did not. Only waist circumference predicted continuous variations in EF. Conclusions. Central adiposity, alcohol consumption, and smoking habits but not physical activity are each independent predictors of poor brachial artery reactivity in patients with or at high risk for cardiovascular disease.
\end{abstract}

\section{Introduction}

Poor endothelial function (EF) predicts future cardiovascular events [1] and is thought to be influenced by several behavioural risk factors for cardiovascular disease (CVD) including smoking, physical activity, obesity, and alcohol consumption. Thus, poor EF may mediate some of the risks for CVD created by these behaviours. For example, current smokers have been found to have lower EF than those who have never smoked [2-6]. Furthermore, smoking has been shown to induce an acute decrease in EF $[4,7]$. To our knowledge, however, there has only been one study that has examined the relationship between lifetime smoking and EF [8]. While this study found that pack/years were inversely related to $\mathrm{EF}$, the generalizability of these results may be limited given the narrow age range of its participants (20-28 years).

Cross-sectional studies have found that sedentary participants display reduced EF compared with athletes [9-11], though inconsistencies have been noted $[12,13]$. While some interventions to increase physical activity have been found to have a positive impact on $\mathrm{EF}[12,14-24]$, others have failed to do so [25-28]. To our knowledge, only two studies have examined the relationship between EF and physical activity in moderately active participants; one study found a significant effect of physical activity on EF in children [29], while the other did not find a relationship in adults [30].

While obesity is influenced by several factors, including physical activity, caloric consumption has been found to be 
the most important predictor of weight loss or gain and caloric restriction to be the most effective means of inducing weight loss [31-33]. As such, although "obesity" is not a behaviour per say, here it will be considered a proxy of longterm excess caloric consumption. Cross-sectional studies have observed obese and overweight participants, classified according to BMI, have worse EF compared to normal weight controls [34-37]. Intervention studies using either gastric bypass surgery [38] or a low-calorie diet [39, 40] have also reported weight loss to result in improvements in EF. However, only one study to date has examined the relationship between obesity and $\mathrm{EF}$ in participants with a wide range of BMIs, finding that both overweight and obese individuals have worse EF than normal weight controls [41].

The effect of alcohol consumption on EF is equivocal. While studies comparing alcoholics to nonalcoholic controls have reported alcoholics to have significantly lower EF [4244], the impact of moderate amounts of alcohol on EF is uncertain. Acute wine consumption has generally been observed to have a positive impact on EF [45-47] though one study found no difference in EF when pairing a glass of red wine versus a control beverage with a high-fat meal [48]. Furthermore, the equivalent of one drink's worth of ethanol has resulted in no acute change in EF [49], while four drinks' worth of ethanol resulted in a significant acute decrease in EF [50]. There has been only one published report on the relationship between moderate alcohol consumption and EF. In this study of 108 men with coronary artery disease, those who drank 1-3 drinks/day had significantly better EF than abstainers, suggesting an inverted J-shaped relationship between alcohol consumption and EF [51].

While the effects of smoking, physical activity, obesity, and alcohol consumption on EF have been examined, some important gaps in knowledge remain. First, there is a lack of research examining the relationship between lifetime smoking and EF. Second, further research is needed to clarify the nature of the relationship between moderate levels of physical activity and EF. Third, studies are needed to clarify the relationship between regular moderate alcohol consumption and EF. Fourth, since most studies on health behaviours and EF have been conducted in generally healthy noncardiac samples, this relationship should be explored in samples that have or are at risk for cardiovascular disease. Finally, since these variables often cooccur, research is needed to determine their independent effects. The primary goal of the current study was to examine the relationship between all four health behaviours and brachial artery reactivity, used as a proxy of $\mathrm{EF}$, in a single sample. This allowed determination of whether each health behaviour had an impact on EF independent of the others and allowed evaluation of their relative impact on EF (Table 1).

\section{Methods}

2.1. Participants. The study was a substudy of the Mechanisms and Outcomes of Silent Myocardial Ischemia (MOSMI) study, a longitudinal study of risk factors for silent ischemia and the impact of silent ischemia on cardiovascular
TABle 1: Summary table.

\begin{tabular}{|c|c|}
\hline pic & What this study adds \\
\hline $\begin{array}{l}\text { an early predictor of future } \\
\text { cardiovascular events. } \\
\text { (ii) Poor health behaviours, } \\
\text { including smoking, sedentary } \\
\text { behaviour, obesity, and } \\
\text { excessive alcohol consumption, } \\
\text { have individually been } \\
\text { associated with endothelial } \\
\text { dysfunction. } \\
\text { (iii) These studies have } \\
\text { generally compared "extreme" } \\
\text { behaviours (e.g., marathon } \\
\text { runners versus sedentary } \\
\text { individuals). }\end{array}$ & $\begin{array}{l}\text { (i) There are independent } \\
\text { effects of current smoking } \\
\text { habits, obesity and alcohol } \\
\text { consumption on brachial artery } \\
\text { reactivity. } \\
\text { (ii) Whilst any improvement in } \\
\text { a single health behaviour might } \\
\text { have a positive influence on } \\
\text { endothelial function, targeting } \\
\text { multiple behaviours should } \\
\text { yield greater benefits. }\end{array}$ \\
\hline
\end{tabular}

outcome. A total of 904 consecutive patients referred for single-photon emission computed tomography (SPECT) exercise stress tests between July 2005 and December 2006 in the Nuclear Medicine Service of the Montreal Heart Institute were recruited. To be eligible for the MOSMI study, patients had to be undergoing SPECT exercise stress testing, be over 18 years old, and speak either English or French. Patients were excluded if they had experienced a cardiac event (e.g., myocardial infarction) in the last 4 weeks, if they had a more prominent medical condition than CVD (e.g., cancer, chronic obstructive pulmonary disease), or were pregnant or nursing. A subsample of 328 patients from the MOSMI study underwent $\mathrm{EF}$ testing. The selection of this group from the main cohort was done based on the random allocation to available testing time slots. There were no differences in age, sex, or CVD status between this subsample and those patients recruited for the MOSMI study but who were not included in final analysis. The MOSMI study was approved by the Human Ethics Committee of the Montreal Heart Institute and written informed consent was obtained from all participants.

2.2. Procedure. Patients presenting to the Nuclear Medicine Service of the Montreal Heart Institute on the day of their exercise stress test were approached to participate in the MOSMI study. Once consent was obtained, demographic and medical information, including health behaviours, was collected using a self-report questionnaire and waist circumference was measured. Patients then underwent standard treadmill exercise stress testing (Bruce protocol) followed by SPECT imaging. As per the SPECT protocol, all patients returned the following day to complete their rest scan. Prior to the rest scan patients underwent the forearm hyperaemic reactivity (FHR) test to measure brachial artery reactivity in response to hyperaemic challenge. All SPECT imaging was conducted according to standard procedure [52-54]. In general, patients were maintained on their usual medication, the only exception being that people were asked to withhold taking beta-blockers on the day of the exercise and rest SPECT studies. 
2.3. Brachial Artery Reactivity Assessment. The FHR technique, implemented by a trained Nuclear Medicine technician, was used to assess brachial artery activity. FHR is considered a marker of $\operatorname{EF}[55,56]$. FHR measures alterations in the brachial artery endothelium following a hyperaemic challenge $[57,58]$. The patient is seated with both arms extended over the top of a standard large fieldof-view gamma camera with a low negative high resolution collimater (Scintronix, London, UK) facing upward, hands prone. To create the hyperaemic challenge, a blood pressure cuff (Adult First Responders, B\&A Instruments, New York, New York) was placed on the right arm and inflated at $50 \mathrm{mmHg}$ above systolic blood pressure for 5 minutes, after which it was released. Forty-five seconds after the cuff was deflated, $0.42 \mathrm{mCi} / \mathrm{kg}$ of the radioactive tracer Tc- $99 \mathrm{~m}$ tetrofosmin (Myoview, Amersham Health, Princeton, NJ) was injected into the patient's arm via a small catheter positioned in the bend of the left arm. For the next 10 minutes, dynamic image acquisitions were realized using 128 $\times 128$ matrices at a sampling rate one frame per second. From this, the ratio between the rate of blood flow into the right (the hyperaemic arm) and left (the control arm) arms, the relative uptake ratio (RUR), was calculated using custommade software (Sygesa, Montreal, Canada). The higher one's RUR, the better the endothelial tissue is at responding to the hyperaemia, via the promotion of vasodilation. Thus, a higher RUR indicates better EF and a lower RUR indicates worse EF. More specifically, an RUR under 3.55 is considered to be indicative of endothelial dysfunction [58]. This technique has a high level of reproducibility with excellent intra- and interrater reliability [59].

\subsection{Health Behaviours}

2.4.1. Physical Activity. Leisure time physical activity was derived from a slightly adapted 12-month version of the Physical Activity Recall Interview [60]. Specifically, given the nature of activity patterns in Montreal, separate details were collected for winter-like and summer-like activities and then combined. Physical activity levels were calculated as average metabolic equivalents MET-hrs/week.

2.4.2. Smoking. Lifetime cigarette consumption was assessed using the standard calculation of pack/years (average number of packs smoked/day $\times$ number of years having smoked) [61]. Patients were also classified as current, ex-, and never smokers.

2.4.3. Obesity. As centrally distributed fat seems to be more significant in the aetiology of CVD [62], waist circumference was used as our measure of central adiposity. Prior to the EF test, the attending technician measured the participants' waist circumference at the mid-point between the superilliac crest and the lower thoracic cavity.

2.4.4. Alcohol. Participants were asked to report their usual daily or weekly consumption of alcoholic beverages. Using this data, weekly units of alcohol consumed were estimated.
TABle 2: Participant characteristics.

\begin{tabular}{lcc}
\hline Variable & $M \pm$ SD or \% $(n)$ & Data missing (\%) \\
\hline Age (yrs) & $59.7 \pm 9.6$ & $1 \%$ \\
Sex (\% women) & $25 \%(83)$ & $0 \%$ \\
Endothelial dysfunction & $44 \%(145)$ & $0 \%$ \\
(RUR $<3.55)$ & $13.4 \pm 12.8$ & $8 \%$ \\
Average \# drinks/week & $99.6 \pm 12.0$ & $3 \%$ \\
Waist circumference (cm) & $7.2 \pm 12.4$ & $1 \%$ \\
Leisure-time physical & & \\
activity (MET-hrs/week) & $15.7 \pm 19.6$ & $9 \%$ \\
Lifetime smoking (pack & Current: 11\% (37) & \\
years) & Previous: $57 \%(188)$ & $0 \%$ \\
Smoking status & Never: $31 \%(102)$ & \\
& $49 \%(157)$ & $3 \%$ \\
Statin use & $26 \%(82)$ & $3 \%$ \\
Ace inhibitor use & $41 \%(133)$ & $0 \%$ \\
Cardiovascular disease & $16 \%(38)$ & $0 \%$ \\
Diabetes & $62 \%(198)$ & $2 \%$ \\
Hypercholesterolemia & $60 \%(196)$ & $0 \%$ \\
Hypertension &
\end{tabular}

2.5. Data Analysis. Our missing data analysis procedures used missing at random (MAR) assumptions, as per Rubin's rules [63]. We used the PROC MI method of multiple multivariate imputation in SAS. We independently analyzed 5 copies of the data, each with missing values imputed, and then used PROC MIANALYZE to average estimates of the variables to give a single mean estimate and adjusted standard errors according to Harrell's guidelines [64]. Details of the amount of missing data per variable are included in Table 2.

To examine the contributions of physical activity, smoking, obesity, and alcohol consumption to EF, a series of GLMs on the individual variables was also conducted, first for the individual health behaviours alone, second with the individual health behaviours and covariates, and third for all four behaviours together and the covariates. Since a nonlinear relationship was expected to exist between alcohol consumption and EF, participants were split into one of three groups in terms of their alcohol consumption. Group 1 consisted of heavy drinkers (defined as 22 or more drinks per week), group 2 consisted of abstainers, and group 3 consisted of moderate drinkers (1-21 drinks per week). The groups were defined as such since consuming 1-3 drinks per day has been associated with better EF than abstinence [51], while 4 or more drinks have been found to negatively impact EF acutely [50]. It was therefore expected that heavy drinkers would have the worst EF and moderate drinkers would have the best $\mathrm{EF}$, creating a linear relationship between group number and EF. Age, sex, CVD status (CVD was defined as having a previous myocardial infarction, stroke, angioplasty, or coronary artery bypass graft), ace inhibitor use, statin use, hypertension, diabetes, and hypercholesterolemia were chosen as covariates a priori, 
as all have been shown to have strong independent effects on $\mathrm{EF}[7,65-71]$. To examine potential interactions between the health behaviours an interaction term for each pair of continuous health behaviours was included one at a time in a GLM including the above-mentioned covariates.

To examine possible associations between the health behaviours and risk of having endothelial dysfunction, defined as an RUR under 3.55, two logistic regression analyses were conducted predicting endothelial dysfunction from all four health behaviours and the covariates together. For these analyses, waist circumference was split into tertiles: $<92 \mathrm{~cm}, 92-108 \mathrm{~cm}$, and $>108 \mathrm{~cm}$. Smoking was defined by smoking status (current/past/never). Alcohol consumption was split by the groups described above. Finally, physical activity was split into tertiles: 0, 0-9.7 and >9.7 METhrs/week.

\section{Results}

The characteristics of the 328 participants are presented in Table 2. The GLM analyses for individual health behaviours revealed that waist circumference $(\beta(\mathrm{SEM})=-.03(.01), P<$ $.0001)$ contributed significantly to EF. A trend for an effect of smoking on EF measured using pack-years $(F=1.78, P=$ $.075)$ was also found. However, physical activity $(\beta$ (SEM) $=-.01(.01), P=.528)$, smoking status $(\beta($ SEM $)=-.22$ (.15), $P=.131)$, and alcohol consumption $(\beta(\mathrm{SEM})=.19$ $(.12), P=.136)$ were not associated with $\mathrm{EF}$ as a continuous variable.

GLMs for the individual health behaviours with age, sex, CVD status, ace inhibitor use, statin use, hypertension, diabetes, and hypercholesterolemia as covariates were then conducted. These analyses revealed that waist circumference $(\beta($ SEM $)=-.04(.01), P<.0001)$ contributed significantly to the variability in EF, while physical activity $(\beta$ (SEM) $=$ $-.01(.01), P=.398)$, alcohol consumption $(\beta(\mathrm{SEM})=-.17$ (.13), $P=.167)$, and smoking measured according to packyears $(\beta($ SEM $)=-.01(.01), P=.203)$ or smoking status $(\beta$ $(\mathrm{SEM})=-.21(.15), P=.153)$ did not.

Results of a GLM with all covariates and health behaviours included revealed that waist circumference was a significant independent predictor of EF considered as a continuous variable (Table 3 and Figure 1). Neither alcohol consumption, physical activity, nor smoking, measured according to pack years were significantly related to $\mathrm{EF}$ (Table 3). Comparable results were found when lifetime smoking was replaced by current smoking status.

The results of the GLMs separately examining the interaction between each pair of health behaviours revealed no significant interaction effects.

A logistic regression analysis, including all covariates and health behaviours in the model revealed that in comparison to the lowest tertile of waist circumference $(<92 \mathrm{~cm})$, being in the second tertile $(92-108 \mathrm{~cm})$ was associated with a $90 \%$ increased risk of endothelial dysfunction ( $\mathrm{OR}=1.90,95 \%$ $\mathrm{CI}=1.01-3.59)$. Being in the third tertile for waist circumference $(>108 \mathrm{~cm})$, on the other hand, was associated with more than double the risk of endothelial dysfunction $(\mathrm{OR}=2.39$, $95 \% \mathrm{CI}=1.15-4.98)$. Alcohol consumption group was also
TABLE 3: Summary of multiple regression analysis for all health behaviours predicting brachial artery reactivity, controlling for age, sex, CVD status, ace inhibitor use, statin use, hypertension, diabetes, and hypercholesterolemia.

\begin{tabular}{lcccc}
\hline Variable & $\beta$ & SE & $t$ & $P$ \\
\hline Waist circumference & -0.03 & 0.01 & -3.95 & $<.000$ \\
Physical activity & -0.01 & 0.01 & -1.01 & .313 \\
Lifetime smoking & -0.00 & 0.01 & -0.86 & .392 \\
Alcohol usage & 0.14 & 0.12 & -1.13 & .258 \\
\hline
\end{tabular}

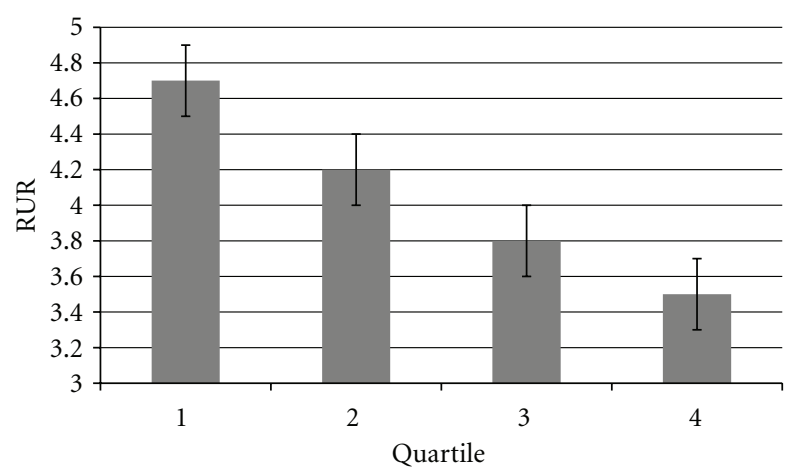

FIGURE 1: Mean relative uptake ratio (RUR) as a function of waist circumference split into quartiles, with standard error bars, adjusting for covariates, smoking, physical activity, and alcohol consumption.

a significant predictor of endothelial dysfunction such that being a nondrinker versus a moderate drinker was associated with nearly double the risk of endothelial dysfunction (OR = $1.99,95 \% \mathrm{CI}=1.08-3.70$ ), while the risk associated with being a heavy drinker did not differ from being a moderate drinker $(\mathrm{OR}=1.57,95 \% \mathrm{CI}=0.82-2.86)$. Being a past smoker versus a never smoker was associated with double the risk of endothelial dysfunction $(\mathrm{OR}=2.00,95 \% \mathrm{CI}=1.26-$ 3.75), while the risk associated with being a current smoker did not reach significance $(\mathrm{OR}=2.17,95 \% \mathrm{CI}=0.88-4.84)$. Finally, the odds ratios for being in the first ( $\mathrm{OR}=0.82,95 \%$ $\mathrm{CI}=0.44-1.53)$ or second tertile $(\mathrm{OR}=1.29,95 \% \mathrm{CI}=0.70$ 2.35 ) in comparison with the third tertile for physical activity were not significant (Figure 2).

\section{Discussion}

This study is the first attempt to assess the effects of waist circumference, physical activity, alcohol consumption, and smoking on EF in a single sample of cardiac patients. The GLM analyses revealed that waist circumference was negatively associated with continuous variations in EF and that there was a trend for a significant negative association between lifetime smoking and EF when they were each included in the model alone. However, when covariates were added to the model, this trend disappeared but the significant effect of waist circumference on EF remained. When all four health behaviours were included in the same model with the covariates, only waist circumference was significantly associated with EF considered as a continuous 


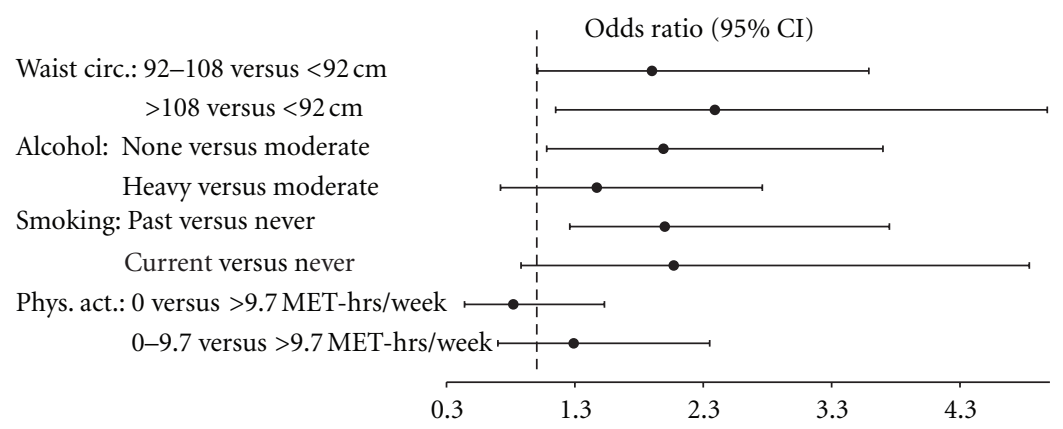

FIGURE 2: Forest plot of odds-ratios and 95\% confidence intervals for the effect of each health behaviour on endothelial dysfunction adjusting for covariates and the other health behaviours.

variable. Additional logistic regression analyses, including all four health behaviours and covariates together, revealed that increased waist circumference also increased risk for clinical endothelial dysfunction. Surprisingly, abstinence from alcohol and past smoking predicted endothelial dysfunction, while heavy alcohol consumption and current smoking did not.

The current findings suggest that central adiposity is negatively associated with EF. Consistent with the current findings, several studies have found measures of central adiposity such as waist circumference and waist-hip ratio, to be predictors of cardiovascular outcomes in patients both with [72] and without [73-77] known CVD. Although the exact mechanism behind this obesity-induced increase in endothelial dysfunction is unclear, two candidate processes have been proposed: (1) via alternations in adipokine levels; and (2) via increases in free fatty acid levels. In brief, it would appear that increasing levels of obesity are associated with increases in adipokines that negatively influence the endothelium [78], and decreases in adipokines that exert positive effects on the endothelium [79]. For example, leptin, which is increased in obese patients, has been shown to increase the release of reactive oxygen species in human endothelial cells [78], thus diminishing the bioavailability of nitric oxide (NO), an important vasodilator and inhibitor of inflammation and platelet aggregation. Alternatively, adiponectin, which is downregulated in obese individuals [79], stimulates nitric oxide production, and promotes vasodilation [80]. Recent studies have also found increased levels of endothelial dysfunction when free fatty acids, which are abundant in patients with abdominal obesity [81], were administered exogenously $[82,83]$. This alteration is thought to occur by free fatty acids decreasing endothelial nitric oxide synthase (eNOS) activity [82].

The findings regarding cigarette smoking and alcohol use are somewhat more complex. That is, GLM analyses indicate that these variables were not associated with continuous fluctuations of EF. However, the logistic regression analyses reveal that past (but not current) smoking and abstinence from alcohol (but not heavy consumption) both increased the risk of endothelial dysfunction. The fact that the odds ratios for current smoking did not reach significance may be partially due to small sample sizes since relatively few participants were current smokers. The finding that past smoking was associated with an increased risk of endothelial dysfunction suggests that smoking-induced endothelial damage is long lasting. This is consistent with previous research finding that the somewhat improved flow-mediated dilation of former smokers was not statistically greater than current smokers [6]. Smoking is thought to damage endothelial cells directly [84] and to increase oxidative stress, thereby decreasing nitric oxide availability [85]. Smoking also appears to reduce the immune system's ability to repair this endothelial damage by decreasing the number of circulating endothelial progenitor cells, which are mobilised in response to vascular injury [86]. Following smoking cessation, the number of circulating endothelial progenitor cells has been found to increase rapidly [87], suggesting that the EF of ex-smokers should begin improving soon after quitting. However, it is unknown to what extent the length of time of smoking or the length of time since quitting impacts current EF. It may therefore be the case that the ex-smokers in the current study had either smoked too long or had not been smoke-free long enough to exhibit fully recovered EF.

Our finding that heavy alcohol consumption is not associated with greater risk of endothelial dysfunction is inconsistent with previous research finding that heavy consumption has been found to induce endothelial cell apoptosis by increasing oxidative stress [88] and impairing nitric oxide production [89]. This finding may therefore be related to sample size, considering the relatively small number of heavy drinkers in the current study. However, that moderate alcohol consumption is associated with better EF than abstinence is consistent with previous findings [51]. It is believed that moderate alcohol consumption may improve EF by increasing NO levels [90] and decreasing homocysteine levels, which is an amino acid causing oxidative stress [91].

That physical activity was not found to be associated with $\mathrm{EF}$ is inconsistent with studies comparing sedentary individuals with athletes [9-11] but is consistent with the one study that has examined the relationship between moderate physical activity and EF in adults [30]. This finding suggests that physical activity may contribute little to EF among moderately active individuals at high risk for cardiovascular disease who likely engage in several poor health behaviours at once. Considering the average participant in this study does not meet the minimum requirements for physical activity set by the American College of Sports Medicine and the 
American Heart Association [92], which is between 7.5 and 12.5 MET-hrs/week, greater levels of physical activity may be needed to see its effect on EF.

Of course, the results of the current study must be considered in light of some limitations. As with all crosssectional studies, it is impossible to draw conclusions about the cause and effect relationship between the health behaviours assessed and EF. The current study also used retrospective self-report measures for physical activity, alcohol consumption, and smoking, which may be susceptible to recall bias. Drink type was also not taken into account for alcohol consumption, which is problematic given that wine has been found to have a unique beneficial effect on EF $[47,93]$. Our failure to record patients' use of nicotine replacement therapy, known to affect EF [94], is also a limitation.

While the current study has its limitations, the fact that it examined the relationship between EF and smoking, obesity, physical activity, and alcohol consumption in the same statistical model is an important and unique strength. While other studies that have examined the effect of only one health behaviour on EF risk overestimating the portion of variance in EF explained by the behaviour, the present study should more accurately estimate the independent effect of each health behaviour on EF. This is particularly true since poor health behaviours tend to aggregate. It is also a strength that this study examined the effect of health behaviours on $\mathrm{EF}$ in a sample of patients at risk for cardiovascular disease since poor health behaviours would be expected to have the most important and imminent impact in this population. Other strengths of this study include its large sample size, the inclusion of several important covariates, and the quality of the health behaviour measures used. Finally, despite the relative novelty of the FHR technique, it has been shown to be highly reliable [59] and reproducible [58, 95].

In conclusion, the results of this study indicate that central adiposity and smoking are independently associated with worsening $\mathrm{EF}$, while moderate alcohol consumption appears to have an independent positive effect on EF. Physical activity, on the other hand, does not seem to be associated with EF when controlling for other health behaviours and relevant covariates. These findings may imply that within a population exhibiting numerous risk factors for cardiovascular disease, weight reduction, smoking cessation, and moderate alcohol consumption should be emphasized and prioritized over increasing physical activity as interventions to improve patients' cardiovascular profiles. This prioritization may be particularly helpful given the difficulty with which individuals change just one health behaviour. Further work is needed to confirm the mechanisms by which central adiposity, smoking and alcohol consumption influence EF. Further research is also needed to examine the effect of health behaviours on EF over a longer period of time to examine how EF changes as a function of health behaviours over time. Future research should also aim to assess the extent to which the relationship between health behaviours and cardiovascular disease is explained by the impact of health behaviours on $\mathrm{EF}$.

\section{Acknowledgments}

The authors would like to thank Philippe Stébenne, Roxanne Pelletier, Silvana Barone, Nadine Bekkouche, and Sandra Pelaez for help with the data collection. Funding for the collection of data was provided by operating grants from the Heart and Stroke Foundation of Quebec and the Canadian Institutes of Health Research (CIHR) (MOP79445 and MOP89965). Personal support was received for Ms. Gordon from the Canadian Hypertension Society (summer studentship) and le Fonds de La recherche en Santé du Québec (FRSQ) (Master's fellowship). Salary support was received for Drs. Bacon and Lavoie (chercheur boursiers) from the FRSQ and a CIHR New Investigator Award (Dr. Bacon).

\section{References}

[1] A. Lerman and A. M. Zeiher, "Endothelial function: cardiac events," Circulation, vol. 111, no. 3, pp. 363-368, 2005.

[2] R. S. Barua, J. A. Ambrose, L. J. Eales-Reynolds, M. C. DeVoe, J. G. Zervas, and D. C. Saha, "Dysfunctional endothelial nitric oxide biosynthesis in healthy smokers with impaired endothelium-dependent vasodilatation," Circulation, vol. 104, no. 16, pp. 1905-1910, 2001.

[3] A. M. Esen, I. Barutcu, M. Acar et al., "Effect of smoking on endothelial function and wall thickness of brachial artery," Circulation Journal, vol. 68, no. 12, pp. 1123-1126, 2004.

[4] W. Kiowski, L. Linder, K. Stoschitzky et al., "Diminished vascular response to inhibition of endothelium-derived nitric oxide and enhanced vasoconstriction to exogenously administered endothelin-1 in clinically healthy smokers," Circulation, vol. 90, no. 1, pp. 27-34, 1994.

[5] A. M. Zeiher, V. Schachinger, and J. Minners, "Long-term cigarette smoking impairs endothelium-dependent coronary arterial vasodilator function," Circulation, vol. 92, no. 5, pp. 1094-1100, 1995.

[6] D. S. Celermajer, K. E. Sorensen, D. Georgakopoulos et al., "Cigarette smoking is associated with dose-related and potentially reversible impairment of endothelium-dependent dilation in healthy young adults," Circulation, vol. 88 , no. 5 , part 1, pp. 2149-2155, 1993.

[7] J. Lekakis, C. Papamichael, C. Vemmos, K. Stamatelopoulos, A. Voutsas, and S. Stamatelopoulos, "Effects of acute cigarette smoking on endothelium-dependent arterial dilatation in normal subjects," American Journal of Cardiology, vol. 81, no. 10, pp. 1225-1228, 1998.

[8] C. P. M. Leeson, M. Kattenhorn, R. Morley, A. Lucas, and J. E. Deanfield, "Impact of low birth weight and cardiovascular risk factors on endothelial function in early adult life," Circulation, vol. 103, no. 9, pp. 1264-1268, 2001.

[9] M. R. Rinder, R. J. Spina, and A. A. Ehsani, "Enhanced endothelium-dependent vasodilation in older endurancetrained men," Journal of Applied Physiology, vol. 88, no. 2, pp. 761-766, 2000.

[10] T. M. Rywik, M. R. Blackman, A. R. Yataco et al., "Enhanced endothelial vasoreactivity in endurance-trained older men," Journal of Applied Physiology, vol. 87, no. 6, pp. 2136-2142, 1999.

[11] B. A. Kingwell, B. Tran, J. D. Cameron, G. L. Jennings, and A. M. Dart, "Enhanced vasodilation to acetylcholine in athletes is 
associated with lower plasma cholesterol," American Journal of Physiology, vol. 270, no. 6, part 2, pp. H2008-H2013, 1996.

[12] C. A. DeSouza, L. F. Shapiro, C. M. Clevenger et al., "Regular aerobic exercise prevents and restores age-related declines in endothelium-dependent vasodilation in healthy men," Circulation, vol. 102, no. 12, pp. 1351-1357, 2000.

[13] S. Taddei, F. Galetta, A. Virdis et al., "Physical activity prevents age-related impairment in nitric oxide availability in elderly athletes," Circulation, vol. 101, no. 25, pp. 2896-2901, 2000.

[14] P. Clarkson, H. E. Montgomery, M. J. Mullen et al., "Exercise training enhances endothelial function in young men," Journal of the American College of Cardiology, vol. 33, no. 5, pp. 1379$1385,1999$.

[15] R. Hambrecht, E. Fiehn, C. Weigl et al., "Regular physical exercise corrects endothelial dysfunction and improves exercise capacity in patients with chronic heart failure," Circulation, vol. 98, no. 24, pp. 2709-2715, 1998.

[16] Y. Higashi, S. Sasaki, S. Kurisu et al., "Regular aerobic exercise augments endothelium-dependent vascular relaxation in normotensive as well as hypertensive subjects: role of endothelium-derived nitric oxide," Circulation, vol. 100, no. 11, pp. 1194-1202, 1999.

[17] A. Lavrencic, B. G. Salobir, and I. Keber, "Physical training improves flow-mediated dilation in patients with the polymetabolic syndrome," Arteriosclerosis, Thrombosis, and Vascular Biology, vol. 20, no. 2, pp. 551-555, 2000.

[18] A. Linke, N. Schoene, S. Gielen et al., "Endothelial dysfunction in patients with chronic heart failure: systemic effects of lowerlimb exercise training," Journal of the American College of Cardiology, vol. 37, no. 2, pp. 392-397, 2001.

[19] A. Maiorana, G. O'Driscoll, C. Cheetham et al., "The effect of combined aerobic and resistance exercise training on vascular function in type 2 diabetes," Journal of the American College of Cardiology, vol. 38, no. 3, pp. 860-866, 2001.

[20] S. Gielen, S. Erbs, A. Linke, S. Möbius-Winkler, G. Schuler, and R. Hambrecht, "Home-based versus hospital-based exercise programs in patients with coronary artery disease: effects on coronary vasomotion," American Heart Journal, vol. 145, no. 1, article E3, p. E3, 2003.

[21] N. Gokce, J. A. Vita, D. S. Bader et al., "Effect of exercise on upper and lower extremity endothelial function in patients with coronary artery disease," American Journal of Cardiology, vol. 90, no. 2, pp. 124-127, 2002.

[22] S. D. Katz, J. Yuen, R. Bijou, and T. H. Lejemtel, “Training improves endothelium-dependent vasodilation in resistance vessels of patients with heart failure," Journal of Applied Physiology, vol. 82, no. 5, pp. 1488-1492, 1997.

[23] M. Vona, A. Rossi, P. Capodaglio et al., "Impact of physical training and detraining on endothelium-dependent vasodilation in patients with recent acute myocardial infarction," American Heart Journal, vol. 147, no. 6, pp. 1039-1046, 2004.

[24] R. Hambrecht, A. Wolf, S. Gielen et al., "Effect of exercise on coronary endothelial function in patients with coronary artery disease," The New England Journal of Medicine, vol. 342, no. 7, pp. 454-460, 2000.

[25] D. J. Green, N. T. Cable, C. Fox, J. M. Rankin, and R. R. Taylor, "Modification of forearm resistance vessels by exercise training in young men," Journal of Applied Physiology, vol. 77, no. 4, pp. 1829-1833, 1994.

[26] B. A. Kingwell, B. Sherrard, G. L. Jennings, and A. M. Dart, "Four weeks of cycle training increases basal production of nitric oxide from the forearm," American Journal of Physiology, vol. 272, no. 3, pp. H1070-H1077, 1997.
[27] A. Maiorana, G. O’Driscoll, L. Dembo, C. Goodman, R. Taylor, and D. Green, "Exercise training, vascular function, and functional capacity in middle-aged subjects," Medicine and Science in Sports and Exercise, vol. 33, no. 12, pp. 20222028, 2001.

[28] T. V. Lewis, A. M. Dart, J. P. F. Chin-Dusting, and B. A. Kingwell, "Exercise training increases basal nitric oxide production from the forearm in hypercholesterolemic patients," Arteriosclerosis, Thrombosis, and Vascular Biology, vol. 19, no. 11, pp. 2782-2787, 1999.

[29] R. A. Abbott, M. A. Harkness, and P. S. W. Davies, "Correlation of habitual physical activity levels with flow-mediated dilation of the brachial artery in 5-10 year old children," Atherosclerosis, vol. 160, no. 1, pp. 233-239, 2002.

[30] D. C. Felmeden, C. G. C. Spencer, A. D. Blann, D. G. Beevers, and G. Y. H. Lip, "Physical activity in relation to indices of endothelial function and angiogenesis factors in hypertension: a substudy of the Anglo-Scandinavian Cardiac Outcomes Trial (ASCOT)," Journal of Internal Medicine, vol. 253, no. 1, pp. 8191, 2003.

[31] J. A. Blumenthal, A. Sherwood, E. C. D. Gullette et al., "Exercise and weight loss reduce blood pressure in men and women with mild hypertension: effects on cardiovascular, metabolic, and hemodynamic functioning," Archives of Internal Medicine, vol. 160, no. 13, pp. 1947-1958, 2000.

[32] K. Elfhag and S. Rössner, "Who succeeds in maintaining weight loss? A conceptual review of factors associated with weight loss maintenance and weight regain," Obesity Reviews, vol. 6, no. 1, pp. 67-85, 2005.

[33] J. M. Jakicic, B. H. Marcus, K. I. Gallagher, M. Napolitano, and W. Lang, "Effect of exercise duration and intensity on weight loss in overweight, sedentary women: a randomized trial," JAMA, vol. 290, no. 10, pp. 1323-1330, 2003.

[34] Y. Higashi, S. Sasaki, K. Nakagawa, H. Matsuura, K. Chayama, and T. Oshima, "Effect of obesity on endothelium-dependent, nitric oxide-mediated vasodilation in normotensive individuals and patients with essential hypertension," American Journal of Hypertension, vol. 14, no. 10, pp. 1038-1045, 2001.

[35] H. O. Steinberg, H. Chaker, R. Leaming, A. Johnson, G. Brechtel, and A. D. Baron, "Obesity/insulin resistance is associated with endothelial dysfunction: implications for the syndrome of insulin resistance," The Journal of Clinical Investigation, vol. 97, no. 11, pp. 2601-2610, 1996.

[36] P. Tounian, Y. Aggoun, B. Dubern et al., "Presence of increased stiffness of the common carotid artery and endothelial dysfunction in severely obese children: a prospective study," The Lancet, vol. 358, no. 9291, pp. 1400-1404, 2001.

[37] K. S. Woo, P. Chook, C. W. Yu et al., "Overweight in children is associated with arterial endothelial dysfunction and intimamedia thickening," International Journal of Obesity, vol. 28, no. 7, pp. 852-857, 2004.

[38] N. Gokce, J. A. Vita, M. McDonnell et al., "Effect of medical and surgical weight loss on endothelial vasomotor function in obese patients," American Journal of Cardiology, vol. 95, no. 2, pp. 266-268, 2005.

[39] M. Raitakari, T. Ilvonen, M. Ahotupa et al., "Weight reduction with very-low-caloric diet and endothelial function in overweight adults: role of plasma glucose," Arteriosclerosis, Thrombosis, and Vascular Biology, vol. 24, no. 1, pp. 124-128, 2004.

[40] S. Sasaki, Y. Higashi, K. Nakagawa et al., "A low-calorie diet improves endothelium-dependent vasodilation in obese patients with essential hypertension," American Journal of Hypertension, vol. 15, no. 4, part 1, pp. 302-309, 2002. 
[41] J. C. Rodríguez-Pérez, F. Rodríguez-Esparragón, O. Hernández-Perera et al., "Obesity is independently associated with coronary endothelial dysfunction in patients with normal or mildly diseased coronary arteries," Journal of the American College of Cardiology, vol. 37, no. 6, pp. 1523-1528, 2001.

[42] G. Maiorano, F. Bartolomucci, V. Contursi et al., "Noninvasive detection of vascular dysfunction in alcoholic patients," American Journal of Hypertension, vol. 12, no. 2, part 1, pp. 137-144, 1999.

[43] C. Di Gennaro, A. Biggi, A. L. Barilli et al., "Endothelial dysfunction and cardiovascular risk profile in long-term withdrawing alcoholics," Journal of Hypertension, vol. 25, no. 2, pp. 367-373, 2007.

[44] R. R. Zilkens, L. Rich, V. Burke, L. J. Beilin, G. F. Watts, and I. B. Puddey, "Effects of alcohol intake on endothelial function in men: a randomized controlled trial," Journal of Hypertension, vol. 21, no. 1, pp. 97-103, 2003.

[45] S. Agewall, S. Wright, R. N. Doughty, G. A. Whalley, M. Duxbury, and N. Sharpe, "Does a glass of red wine improve endothelial function?" European Heart Journal, vol. 21, no. 1, pp. 74-78, 2000.

[46] C. Papamichael, E. Karatzis, K. Karatzi et al., "Red wine's antioxidants counteract acute endothelial dysfunction caused by cigarette smoking in healthy nonsmokers," American Heart journal, vol. 147, no. 2, article E5, 2004.

[47] A. P. Whelan, W. H. F. Sutherland, M. P. McCormick, D. J. Yeoman, S. A. De Jong, and M. J. A. Williams, "Effects of white and red wine on endothelial function in subjects with coronary artery disease," Internal Medicine Journal, vol. 34, no. 5, pp. 224-228, 2004.

[48] L. Djoussé, R. C. Ellison, C. E. McLennan et al., "Acute effects of a high-fat meal with and without red wine on endothelial function in healthy subjects," American Journal of Cardiology, vol. 84, no. 6, pp. 660-664, 1999.

[49] C. Vlachopoulos, D. Tsekoura, E. Tsiamis, D. Panagiotakos, and C. Stefanadis, "Effect of alcohol on endothelial function in healthy subjects," Vascular Medicine, vol. 8, no. 4, pp. 263265, 2003.

[50] P. F. D. Bau, C. H. D. Bau, A. A. Naujorks, and G. A. Rosito, "Early and late effects of alcohol ingestion on blood pressure and endothelial function," Alcohol, vol. 37, no. 1, pp. 53-58, 2006.

[51] H. Teragawa, Y. Fukuda, K. Matsuda et al., "Effect of alcohol consumption on endothelial function in men with coronary artery disease," Atherosclerosis, vol. 165, no. 1, pp. 145-152, 2002.

[52] C. Anagnostopoulos, M. Harbinson, A. Kelion et al., "Procedure guidelines for radionuclide myocardial perfusion imaging," Heart, vol. 90, no. 1, pp. 1-10, 2004.

[53] American College of Sports Medicine, Guidelines for Exercise Testing and Prescription, Lippincott Williams \& Wilkins, Philadelphia, Pa, USA, 6th edition, 2000.

[54] American Society of Nuclear Cardiology, "Updated imaging guidelines for nuclear cardiology procedures. Part 1," Journal of Nuclear Cardiology, vol. 8, no. 1, pp. G5-G58, 2001.

[55] A. Barac, U. Campia, and J. A. Panza, "Methods for evaluating endothelial function in humans," Hypertension, vol. 49, no. 4, pp. 748-760, 2007.

[56] J. E. Deanfield, J. P. Halcox, and T. J. Rabelink, "Endothelial function and dysfunction: testing and clinical relevance," Circulation, vol. 115, no. 10, pp. 1285-1295, 2007.
[57] K. L. Lavoie, R. Pelletier, A. Arsenault, J. Dupuis, and S. L. Bacon, "Association between clinical depression and endothelial function measured by forearm hyperemic reactivity," Psychosomatic Medicine, vol. 72, no. 1, pp. 20-26, 2010.

[58] J. Dupuis, A. Arsenault, B. Meloche, F. Harel, C. Staniloae, and J. Grégoire, "Quantitative hyperemic reactivity in opposed limbs during myocardial perfusion imaging: a new marker of coronary artery disease," Journal of the American College of Cardiology, vol. 44, no. 7, pp. 1473-1477, 2004.

[59] J. V. Zanten, B. Meloche, S. Bacon, P. Stébenne, A. Arsenault, and K. Lavoie, "Inter-observer reliability of a new method to measure endothelial function," Psychosomatic Medicine, vol. 68, no. A36, 2006.

[60] R. S. Paffenbarger, S. N. Blair, I. M. Lee, and R. T. Hyde, "Measurement of physical activity to assess health effects in free-living populations," Medicine and Science in Sports and Exercise, vol. 25, no. 1, pp. 60-70, 1993.

[61] C. M. Bernaards, J. W. R. Twisk, J. Snel, W. Van Mechelen, and H. C. G. Kemper, "Is calculating pack-years retrospectively a valid method to estimate life-time tobacco smoking? A comparison between prospectively calculated pack-years and retrospectively calculated pack-years," Addiction, vol. 96, no. 11, pp. 1653-1691, 2001.

[62] I. Ferreira, M. B. Snijder, J. W. R. Twisk et al., "Central fat mass versus peripheral fat and lean mass: opposite (adverse versus favorable) associations with arterial stiffness? The Amsterdam growth and health longitudinal study," Journal of Clinical Endocrinology and Metabolism, vol. 89, no. 6, pp. 2632-2639, 2004.

[63] F. Harrell, Regression Modeling Strategies, Springer, New York, NY, USA, 2001.

[64] D. B. Rubin, Multiple Imputation for Nonresponse in Surveys, John Wiley \& Sons, New York, NY, USA, 1987.

[65] M. Hashimoto, M. Akishita, M. Eto et al., "Modulation of endothelium-dependent flow-mediated dilatation of the brachial artery by sex and menstrual cycle," Circulation, vol. 92, no. 12, pp. 3431-3435, 1995.

[66] C. P. Tiefenbacher, S. Friedrich, T. Bleeke, C. Vahl, X. Chen, and F. Niroomand, "ACE inhibitors and statins acutely improve endothelial dysfunction of human coronary arterioles," American Journal of Physiology, vol. 286, no. 4, pp. H1425-H1432, 2004.

[67] N. Andrawis, D. S. Jones, and D. R. Abernethy, "Aging is associated with endothelial dysfunction in the human forearm vasculature," Journal of the American Geriatrics Society, vol. 48, no. 2, pp. 193-198, 2000.

[68] P. L. Ludmer, A. P. Selwyn, and T. L. Shook, "Paradoxical vasoconstriction induced by acetylcholine in atherosclerotic coronary arteries," The New England Journal of Medicine, vol. 315, no. 17, pp. 1046-1051, 1986.

[69] E. Maggi, R. Chiesa, G. Melissano et al., "LDL oxidation in patients with severe carotid atherosclerosis: a study of in vitro and in vivo oxidation markers," Arteriosclerosis and Thrombosis, vol. 14, no. 12, pp. 1892-1899, 1994.

[70] B. Guerci, P. Böhme, A. Kearney-Schwartz, F. Zannad, and P. Drouin, "Endothelial dysfunction and type 2 diabetes. Part 2: altered endothelial function and the effects of treatments in type 2 diabetes mellitus," Diabetes and Metabolism, vol. 27, no. 4, pp. 436-447, 2001.

[71] J. A. Panza, "Endothelial dysfunction in essential hypertension," Clinical Cardiology, vol. 20, no. 12, pp. II26-II33, 1997.

[72] G. R. Dagenais, Q. Yi, J. F. E. Mann, J. Bosch, J. Pogue, and S. Yusuf, "Prognostic impact of body weight and abdominal 
obesity in women and men with cardiovascular disease," American Heart Journal, vol. 149, no. 1, pp. 54-60, 2005.

[73] L. Lapidus, C. Bengtsson, and B. Larsson, "Distribution of adipose tissue and risk of cardiovascular disease and death: a 12 year follow up of participants in the population study of women in Gothenburg, Sweden," British Medical Journal, vol. 289, no. 6454, pp. 1257-1261, 1984.

[74] K. M. Rexrode, J. E. Buring, and J. E. Manson, "Abdominal and total adiposity and risk of coronary heart disease in men," International Journal of Obesity, vol. 25, no. 7, pp. 1047-1056, 2001.

[75] E. B. Rimm, M. J. Stampfer, E. Giovannucci et al., "Body size and fat distribution as predictors of coronary heart disease among middle-aged and older US men," American Journal of Epidemiology, vol. 141, no. 12, pp. 1117-1127, 1995.

[76] A. R. Folsom, L. H. Kushi, K. E. Anderson et al., "Associations of general and abdominal obesity with multiple health outcomes in older women: the Iowa Women's Health Study," Archives of Internal Medicine, vol. 160, no. 14, pp. 2117-2128, 2000.

[77] H. M. Lakka, T. A. Lakka, J. Tuomilehto, and J. T. Salonen, "Abdominal obesity is associated with increased risk of acute coronary events in men," European Heart Journal, vol. 23, no. 9, pp. 706-713, 2002.

[78] A. Bouloumié, T. Marumo, M. Lafontan, and R. Busse, "Leptin induces oxidative stress in human endothelial cells," The FASEB Journal, vol. 13, no. 10, pp. 1231-1238, 1999.

[79] E. Hu, P. Liang, and B. M. Spiegelman, "AdipoQ is a novel adipose-specific gene dysregulated in obesity," The Journal of Biological Chemistry, vol. 271, no. 18, pp. 10697-10703, 1996.

[80] H. Chen, M. Montagnani, T. Funahashi, I. Shimomura, and M. J. Quon, "Adiponectin stimulates production of nitric oxide in vascular endothelial cells," The Journal of Biological Chemistry, vol. 278, no. 45, pp. 45021-45026, 2003.

[81] M. D. Jensen, M. W. Haymond, R. A. Rizza, P. E. Cryer, and J. M. Miles, "Influence of body fat distribution on free fatty acid metabolism in obesity," The Journal of Clinical Investigation, vol. 83, no. 4, pp. 1168-1173, 1989.

[82] H. O. Steinberg, G. Paradisi, G. Hook, K. Crowder, J. Cronin, and A. D. Baron, "Free fatty acid elevation impairs insulinmediated vasodilation and nitric oxide production," Diabetes, vol. 49, no. 7, pp. 1231-1238, 2000.

[83] S. Vigili de Kreutzenberg, C. Crepaldi, S. Marchetto et al., "Plasma free fatty acids and endothelium-dependent vasodilation: effect of chain-length and cyclooxygenase inhibition," Journal of Clinical Endocrinology and Metabolism, vol. 85, no. 2, pp. 793-798, 2000.

[84] S. Hoshino, M. Yoshida, K. Inoue et al., "Cigarette smoke extract induces endothelial cell injury via JNK pathway," Biochemical and Biophysical Research Communications, vol. 329, no. 1, pp. 58-63, 2005.

[85] R. Puranik and D. S. Celermajer, "Smoking and endothelial function," Progress in Cardiovascular Diseases, vol. 45, no. 6, pp. 443-458, 2003.

[86] E. Shantsila, T. Watson, and G. Y. H. Lip, "Endothelial progenitor cells in cardiovascular disorders," Journal of the American College of Cardiology, vol. 49, no. 7, pp. 741-752, 2007.

[87] T. Kondo, M. Hayashi, K. Takeshita et al., "Smoking cessation rapidly increases circulating progenitor cells in peripheral blood in chronic smokers," Arteriosclerosis, Thrombosis, and Vascular Biology, vol. 24, no. 8, pp. 1442-1447, 2004.
[88] G. Soardo, D. Donnini, R. Varutti et al., "Alcohol-induced endothelial changes are associated with oxidative stress and are rapidly reversed after withdrawal," Alcoholism, vol. 29, no. 10, pp. 1889-1898, 2005.

[89] M. G. Persson and L. E. Gustafsson, "Ethanol can inhibit nitric oxide production," European Journal of Pharmacology, vol. 224, no. 1, pp. 99-100, 1992.

[90] R. J. Hendrickson, P. A. Cahill, J. V. Sitzmann, and E. M. Redmond, "Ethanol enhances basal and flow-stimulated nitric oxide synthase activity in vitro by activating an inhibitory guanine nucleotide binding protein," Journal of Pharmacology and Experimental Therapeutics, vol. 289, no. 3, pp. 1293-1300, 1999.

[91] G. N. Welch, G. R. Upchurch Jr., and J. Loscalzo, "Homocysteine, oxidative stress, and vascular disease," Hospital Practice, vol. 32, no. 6, pp. 81-92, 1997.

[92] W. L. Haskell, I. M. Lee, R. R. Pate et al., "Physical activity and public health: updated recommendation for adults from the American College of Sports Medicine and the American Heart Association," Circulation, vol. 116, no. 9, pp. 1081-1093, 2007.

[93] M. Hashimoto, S. Kim, M. Eto et al., "Effect of acute intake of red wine on flow-mediated vasodilatation of the brachial artery," American Journal of Cardiology, vol. 88, no. 12, pp. 1457-1460, 2001.

[94] T. Neunteufl, S. Heher, K. Kostner et al., "Contribution of nicotine to acute endothelial dysfunction in long-term smokers," Journal of the American College of Cardiology, vol. 39, no. 2, pp. 251-256, 2002.

[95] B. Meloche, A. Arsenault, K. L. Lavoie, and S. L. Bacon, "Test-retest reliability of a new method to measure endothelial function," Psychosomatic Medicine, vol. 67, article A54, 2005. 


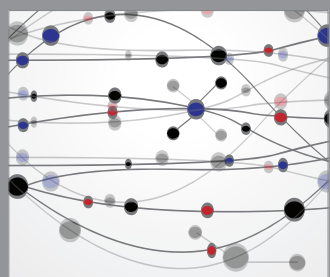

The Scientific World Journal
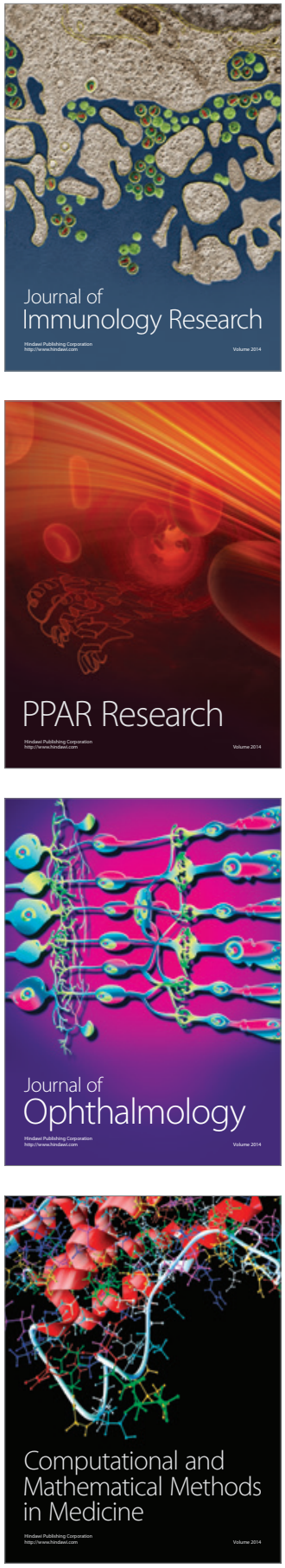

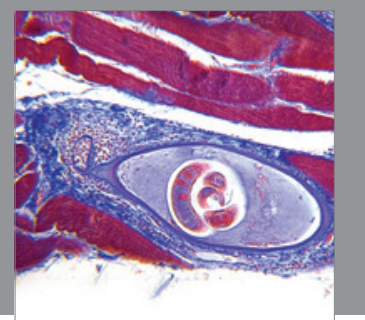

Gastroenterology

Research and Practice
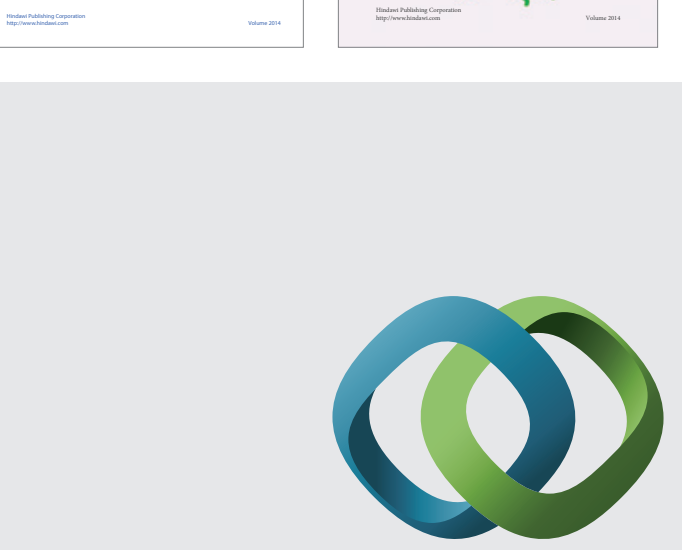

\section{Hindawi}

Submit your manuscripts at

http://www.hindawi.com
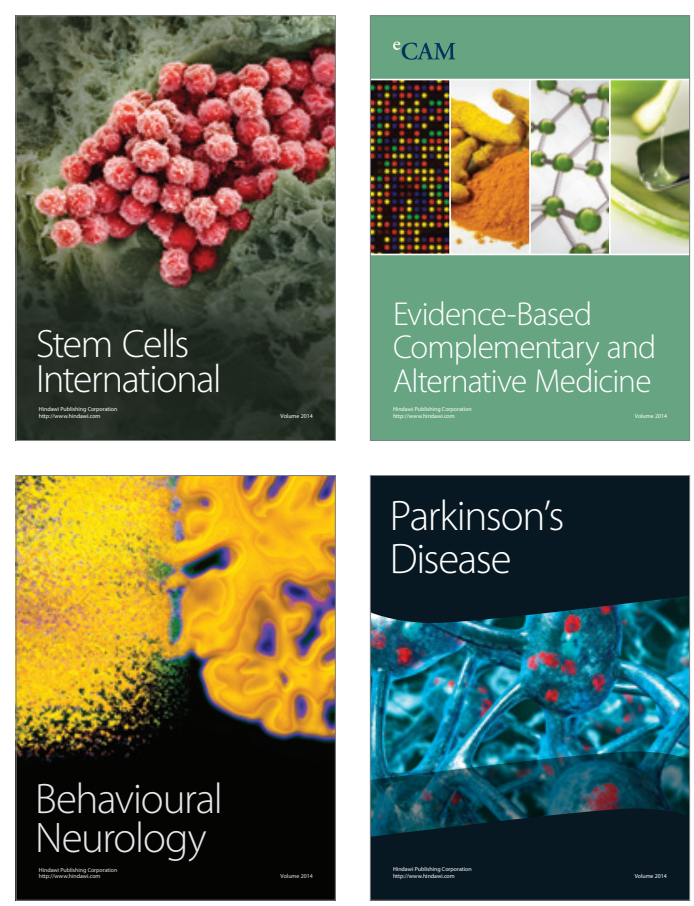

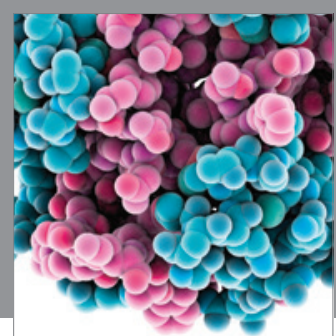

Journal of
Diabetes Research

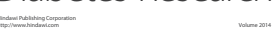

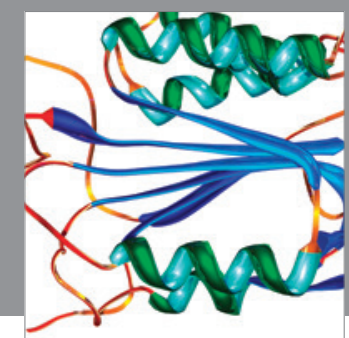

Disease Markers
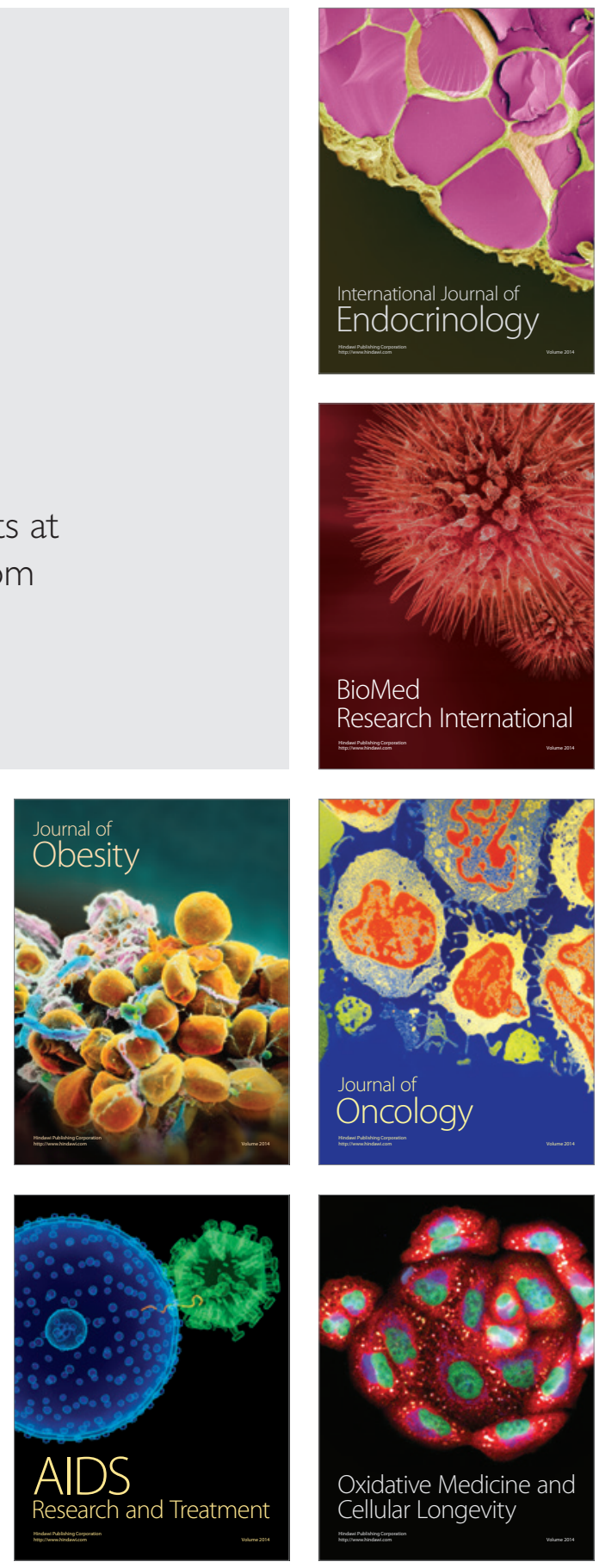